\title{
MECHANISM OF FORMATION OF CORPORA LUTEA IN GUINEA-PIGS
}

\author{
J. P. ALDRED, * P. H. SAMMELWITZ $\dagger$ AND A. V. NALBANDOV \\ Department of Animal Science, University of Illinois, Urbana, U.S.A.
}

(Received 17th March 1961)

Summary. High doses of progesterone can apparently inhibit secretion or release of hypophyseal hormones, including the luteotrophic hormone (LTH). Injection of progesterone into non-pregnant and pregnant guinea-pigs led to partial destruction of formed corpora lutea but did not prevent their initial formation.

The data presented suggest that in the guinea-pig LTH is released about the time of ovulation, but for a period of less than 3 days. This temporary release of $\mathbf{L T H}$ is sufficient to initiate formation and function of corpora lutea. No further LTH support seems to occur in non-pregnant females.

In pregnant animals, a neurohumoral signalling mechanism initiated by intrauterine events of implantation is assumed to call forth a second release of hypophyseal LTH, which is responsible for the maintenance of corpora lutea during the remainder of their functional life span during gestation. Prolactin is not luteotrophic in guinea-pigs.

\section{INTRODUCTION}

In a companion paper (Sammelwitz, Aldred \& Nalbandov, 1961), experimental data are presented which suggest that the growth of corpora lutea in normal oestrous cycles of pigs and rats is governed by a single release of hypophyseal luteotrophic hormone (LTH) which seems to occur at about the time of ovulation, and that corpora lutea of cycles get no further support from hypophyseal LTH during their normal life span. Furthermore, these data suggest that additional hypophyseal LTH release occurs if pigs become pregnant and that this release is triggered by the events of implantation in the uterus. In pregnant rats, the additional LTH necessary to maintain corpora lutea of pregnancy may come from the placenta (as had been noted by other workers) and not from the pituitary gland.

These conclusions were reached on the basis of experiments in which progesterone was injected into non-pregnant and pregnant animals beginning at the time of heat and the rates of luteinization or luteolysis were studied at various intervals after initiation of treatment. A number of questions remained unanswered in these studies and work was continued on guinea-pigs using essentially the same methods as those described for pigs and rats.

* Department of Animal Science, Purdue University, Lafayette, Indiana, U.S.A.

+ Department of Animal and Poultry Industry, University of Delaware, Newark, Delaware, U.S.A. 


\section{MATERIALS AND METHODS}

A total of 120 virgin female albino guinea-pigs weighing 300 to $500 \mathrm{~g}$ was used in three different phases of the experiment, in two of which the effect of progesterone on corpus luteum survival was tested; in the third phase, the ability of prolactin to prolong the life span of corpora lutea was investigated. The females were exposed to fertile males at their second or third heat, and the date of mating was determined by the presence of spermatozoa in vaginal smears taken daily while the vagina was open. The animals were randomly divided into three groups: control group A received no treatment; Group B received daily subcutaneous injections of progesterone beginning on the day following mating (Day 1); while Group $\mathrm{C}$ received daily progesterone injections beginning on the 4th day following mating. Comparisons of weights of ovaries, placentae and foetuses, and of the number of foetuses per animal in relation to the number of corpora lutea were made between and within treatment groups. Sizes and histology of corpora lutea were also compared between the three treatment groups. In most experiments, crystalline progesterone dissolved in propylene glycol was injected at the rate of $8 \mathrm{mg} / \mathrm{kg}$ of body weight.

In order to establish a normal pattern of development of corpora lutea, animals in the control group (A) were subdivided into five groups each containing three animals, and were autopsied at $5,10,15,20$ or 25 days following mating. Group B, which received progesterone from Day 1 of pregnancy, was subdivided into four groups of five animals each, and autopsy was performed at $5,10,20$ or 25 days following mating. Since in Group C progesterone injection was begun at the 4th day of pregnancy, only three subgroups of five animals each were used, autopsy occurring on Days 10, 20 or 25 of pregnancy.

At autopsy, the reproductive tracts were removed and the ovaries were examined under a low-power dissecting microscope for the number (later verified by sectioning), size and vascularity of corpora lutea. The ovaries were then dissected free and fixed in Bouin's solution before being weighed on a torsion balance. When appropriate, the uteri were flushed to determine the number of blastocysts or the number of embryos they contained.

The weights of the uterus including contents, as well as the weights of foetuses, foetal placentae and maternal placentae were also obtained.

All ovaries were serially sectioned at $10 \mu$ and stained. The cross sectional area (in $\mathrm{mm}^{2}$ ) of each corpus luteum was determined in that serial section in which this structure presented the largest area.

The histology of corpora lutea of control animals at various stages of pregnancy was compared to that of corpora lutea of animals treated with progesterone. This comparison was made in such a way that the treatment remained unknown until after the examination of slides.

To determine whether prolactin is luteotrophic in guinea-pigs, forty guineapigs were used in the third phase of the experiment. Injections of doses of prolactin varying from $0 \cdot 16$ to $2 \cdot 50 \mathrm{mg}$ /day were begun on Days $6,8,10$ or 12 following the 1st day of vaginal opening of the normal cycle and continued until Day 20. At autopsy, ovarian and uterine weights were recorded, and macroscopic and microscopic observations were made for the presence of functional corpora lutea. 


\section{RESULTS}

It was found that the injection of $8 \mathrm{mg}$ of progesterone per $\mathrm{kg}$ of body weight per day for 25 days into pregnant guinea-pigs had no significantly deleterious effects on the number of foetuses or on the implantation rate (Table 1). However, by Day 25 of gestation, the average foetus weight was significantly lower in the progesterone-treated groups than in the controls. The placentae also weighed significantly less on Day 25 of pregnancy if the progesterone injections were begun on Day 1 of pregnancy. There were no significant differences in these comparisons if onset of progesterone injections was delayed until Day 4.

TABLE 1

EFFECT OF INJECTION OF PROGESTERONE ( $8 \mathrm{MG} / \mathrm{KG} / \mathrm{DAY}$ ) BEGUN ON DAY 1 OR DAY 4 OF GESTATION ON THE REPRODUCTIVE PERFORMANCE OF GUINEA-PIGS

\begin{tabular}{|c|c|c|c|c|}
\hline \multirow{2}{*}{$\begin{array}{c}\text { Mating to autopsy } \\
(\text { days })\end{array}$} & \multicolumn{2}{|c|}{ Average $\mathcal{N} o}$. & \multicolumn{2}{|c|}{ Average weight $(g)$} \\
\hline & Corpora lutea & Foetuses & Foetuses & Placenta \\
\hline $\begin{array}{c}\text { Control } \\
5 \\
10 \\
20 \\
25\end{array}$ & $\begin{array}{c}\text { Average impla } \\
2 \cdot 6 \\
3 \cdot 0 \\
3 \cdot 0 \\
3 \cdot 6\end{array}$ & $\begin{array}{l}\text { rate } 97.8 \% \\
2 \cdot 6 \\
3 \cdot 0 \\
3 \cdot 0 \\
3 \cdot 0\end{array}$ & $\begin{array}{r}- \\
-\overline{11} \\
0 \cdot 95\end{array}$ & $\begin{array}{l}-.-5 \\
0 \cdot 5 \\
2 \cdot 2 \\
4 \cdot 8\end{array}$ \\
\hline $\begin{array}{c}\text { Progesterone Day } 1 \\
5 \\
10 \\
20 \\
25\end{array}$ & $\begin{array}{c}\text { Average impla } \\
3 \cdot 2 \\
3 \cdot 0 \\
2 \cdot 8 \\
3 \cdot 3\end{array}$ & $\begin{array}{l}\text { rate } 89 \cdot 8 \% \\
2 \cdot 2 \\
2 \cdot 5 \\
3 \cdot 0 \\
3 \cdot 3\end{array}$ & $\begin{array}{l}- \\
-\overline{10} \\
0 \cdot 55^{*}\end{array}$ & $\begin{array}{l}0 \cdot \overline{5} \\
2 \cdot 3 \\
3 \cdot 5 *\end{array}$ \\
\hline $\begin{array}{c}\text { Progesterone Day } 4 \\
5 \\
10 \\
20 \\
25\end{array}$ & $\begin{array}{c}\text { Average impla } \\
3.0 \\
3.0 \\
2.6 \\
3.0\end{array}$ & $\begin{array}{l}\text { rate } 100 \% \\
- \\
3 \cdot 0 \\
2 \cdot 6 \\
3 \cdot 0\end{array}$ & $\begin{array}{c}\overrightarrow{-} \\
0 . \overline{10} \\
0.73 *\end{array}$ & $\begin{array}{l}0 \cdot \overline{4} \\
2 \cdot 2 \\
4 \cdot 6\end{array}$ \\
\hline
\end{tabular}

* $P<0.5$ compared to control animals.

$+P<0.1$ compared to control animals.

Comparison of the effects of progesterone treatment on ovarian weight (Table 2) shows that the ovaries weigh considerably less on most sample points, but on some of them the differences in weight miss statistical significance due to limited numbers of animals. This reduction in ovarian size is attributed to the inhibitory effect of progesterone on the gonadotrophic complex which, in turn, lead to a reduction in the number and size of ovarian follicles. In comparing the effects of treatments on size of corpora lutea, it was found that the 8-mg dose of progesterone begun on Day 1 caused a very significant reduction in the size of corpora lutea to a level below that of control animals. However, if injections were delayed until Day 4 of pregnancy, this dose of progesterone was clearly unable to suppress the development of corpora lutea, at least up to Day 20 of gestation (Table 2).

While progesterone treatment did not reduce the number of corpora lutea 
(as it did in pigs), it had an obvious effect on their prominence, size, vascularity, colour and histological appearance. As early as Day 5 of pregnancy, corpora lutea of treated females had many luteal cells with pycnotic nuclei and showed significantly more infiltration with connective tissue than did the corpora lutea of control females. By Day 25 of pregnancy, corpora lutea of treated females had few functional-appearing luteal cells, many large vacuoles and an extreme degree of infiltration with connective tissue.

Prolactin was found to be definitely not luteotrophic in the guinea-pig since it was unable to prolong the life span of corpora lutea during the normal cycle regardless of whether its injection was begun on Days 6, 8, 10 or 12 after the

TABLE 2

EFFECT OF PROGESTERONE INJECTIONS ( $8 \mathrm{MG} / \mathrm{KG} / \mathrm{DAY}$ ) ON OVARIES AND CORPORA LUTEA OF PREGNANT GUINEA-PIGS

\begin{tabular}{|c|c|c|c|c|c|c|c|c|}
\hline \multirow{3}{*}{$\begin{array}{c}\text { Mating } \\
\text { to first } \\
\text { injection } \\
\text { (days) }\end{array}$} & \multicolumn{8}{|c|}{ No. days from mating to autopsy } \\
\hline & 5 & 10 & 20 & 25 & 5 & 10 & 20 & 25 \\
\hline & \multicolumn{4}{|c|}{ Weight ovaries $(\mathrm{mg})$} & \multicolumn{4}{|c|}{ Area corpora lutea $\left(\mathrm{mm}^{2}\right)$} \\
\hline $\begin{array}{c}\text { Control } \\
1 \\
4\end{array}$ & $\begin{array}{l}92 \\
64 \dagger \\
-\end{array}$ & $\begin{array}{l}110 \\
117 \\
110\end{array}$ & $\begin{array}{c}121 \\
92 \\
93+\end{array}$ & $\begin{array}{c}138 \\
98 \\
92 \dagger\end{array}$ & $\begin{array}{l}0 \cdot 82 \\
0 \cdot 64+ \\
-\end{array}$ & $\begin{array}{l}0.87 \\
0.74 \\
0.80\end{array}$ & $\begin{array}{l}1.26 \\
0.80 \\
1.32\end{array}$ & $\begin{array}{l}1.51 \\
0.55 * \\
1.03\end{array}$ \\
\hline
\end{tabular}

* Significant at $P<\cdot 05$ compared to control animals.

† Significant at $P<\cdot 01$ compared to control animals.

Ist day of vaginal opening and regardless of whether the daily dose was as low as $0.16 \mathrm{mg}$ or as high as $2.50 \mathrm{mg}$. Neither did progesterone treatment have any effect on the size of corpora lutea.

\section{DISCUSSION}

The data presented for guinea-pigs are similar to those obtained in pigs in that they show that progesterone injection into pregnant animals is apparently able to depress hypophyseal LTH secretion which, in turn, is reflected in a reduction of the size of corpora lutea. The difference between guinea-pigs and pigs lies in the fact that in the latter progesterone injected from day of mating until Day 10 of pregnancy was unable to prevent the initial formation of corpora lutea or to reduce the amount of luteal tissue formed. This was interpreted to mean that in pigs there may be single outpouring of LTH which is sufficient to luteinize ovulated follicles and to maintain the resulting corpora lutea for their normal life span during the cycle. In guinea-pigs, the situation is not as clear-cut as it is in the domestic pig. It will be noted (Table 2) that when progesterone injections were begun on Day 1 (e.g., on the average about $24 \mathrm{hr}$ after mating and about 10 to $12 \mathrm{hr}$ after ovulation) the size of the corpora lutea was definitely decreased. This can be interpreted to mean that in the guinea-pig LTH release is not a single short outpouring as it seems to be in the pig and in the rat, but that it 
extends over a period of 24 to $48 \mathrm{hr}$ but lasts less than $96 \mathrm{hr}$. This conclusion is based on the comparison of area of corpora lutea of guinea-pigs injected from Days 1 to 20 of pregnancy with those of the females injected from Days 4 to 20 of pregnancy. While in the former, corpus luteum size was depressed, in the latter progesterone injection was unable to reduce the size of these structures. This is interpreted to mean that progesterone injections begun on Day 1 can depress LTH secretion, while a delay to Day 4 is ineffective because by that time the pituitary gland no longer secretes LтH.

Next, attention is directed to the fact that on Day 25 of pregnancy (Table 2) both doses of progesterone begun on either Day 1 or Day 4 of pregnancy caused a substantial and significant reduction in the area of corpora lutea. This is in good agreement with the observations made on pigs, in which it was found that while progesterone was unable to prevent the formation of corpora lutea it was capable of destroying these structures after they had become fully formed. It is postulated that in pregnant animals a second release of LTH occurs between Day 20 and Day 25 of pregnancy and it is this second release that is being blocked by progesterone injection. In view of the work of Moore \& Nalbandov (1953) and Hansel (1959), which suggests that uterine contents play a role in the release of hypophyseal LTH and thus affect the life span of corpora lutea, it appears possible that the secondary release of LTH is caused by the phenomena occurring at the time of implantation.

On the basis of the data presented or discussed, the following interpretation of events appears justified. A single release of LTH occurs about the time of ovulation and it appears to be of very short duration in pigs and rats, but in guinea-pigs it may last for as long as 3 days. This single release is sufficient to initiate formation of corpora lutea. It seems that corpora lutea do not need additional LTH support for maintenance during the normal non-fertile cycle. If guinea-pigs or domestic pigs become pregnant, a neurohumoral mechanism, triggered by the intrauterine events of implantation, signals for a second outpouring of hypophyseal LтH which presumably continues to be secreted during part or all of the period of gestation.

In a similar study performed in sheep (Zimbelman, Pope \& Casida, 1959), it was found that the greatest depression in corpus luteum weight was obtained when progesterone injections were given during the first five days of pregnancy. Sheep appear to be similar to guinea-pigs in that, with the doses of progesterone used, LTH secretion could not be blocked completely.

There seems to be a significant species difference in the susceptibility of the pituitary gland to the inhibiting action of progesterone, and the apparent differences obtained between the species may be due to greater sensitivity of the pituitary gland of pigs to progesterone leading to complete destruction of corpora lutea, while a lesser sensitivity in guinea-pigs and sheep resulted in only partial inhibition.

\section{ACKNOWLEDGMENTS}

Partial support of this study by the Population Council, Rockefeller Institute, New York, is gratefully acknowledged. The prolactin used was donated by the Endocrine Study Section of the National Institutes of Health. 


\section{Formation of corpora lutea in guinea-pigs \\ REFERENGES}

HANSEL, W. (1959) Further studies on the regulation of the bovine estrous cycle by oxytocin injections. 7. Dairy Sci. 42, 940.

Moore, W. W. \& Nalbandov, A. V. (1953) Neurogenic effects of uterine distention on the estrous cycle of the ewe. Endocrinology, 53, 1 .

Sammelwitz, P. H., Aldred, P. J. \& Nalbandov, A. V. (1961) Mechanisms of maintenance of corpora lutea in pigs and rats. F. Reprod. Fertil. 2, 387.

Zimbelman, R. G., Pope, A. L. \& CAsida, L. E. (1959) Effect of exogenous progesterone on the corpus luteum of the bred ewe. F. Anim. Sci. 18, 1327. 